\title{
Feasibility of a Healthy Trolley Index to assess dietary quality of the household food supply
}

\author{
Amanda Taylor ${ }^{1}$, Freya Wilson ${ }^{1}$, Gilly A. Hendrie ${ }^{2 *}$, Margaret Allman-Farinelli ${ }^{1}$ and Manny Noakes $^{2}$ \\ ${ }^{1}$ School of Molecular Bioscience, Charles Perkins Centre, University of Sydney, NSW 2006, Australia \\ ${ }^{2}$ Commonwealth Scientific and Industrial Research Organisation (CSIRO) Food and Nutrition Flagship, PO Box 10041, \\ Adelaide, SA 5000, Australia
}

(Submitted 3 March 2015 - Final revision received 24 August 2015 - Accepted 2 September 2015 - First published online 15 October 2015)

\begin{abstract}
Supermarket receipts have the potential to provide prospective, objective information about the household food supply. The aim of this study was to develop an index to estimate population diet quality using food purchase data. Supermarket receipt data of 1 month were available for 836 adults from a corporate office of a large retail chain. Participants were aged 19-65 years (mean 37.6 (sD 9.3) years), $56 \%$ were female and $63 \%$ were overweight or obese. A scoring system (Healthy Trolley Index (HETI)) was developed to compare food expenditure with the Australian Guide to Healthy Eating. Monthly expenditure per food group, as a proportion of total food expenditure, was compared with food group recommendations, and a HETI score was calculated to estimate overall compliance with guidelines. Participants spent the greatest proportion on discretionary foods, which are high in fat/sugar (34.8\%), followed by meat including beef and chicken (17.0\%), fresh and frozen vegetables (13.5\%) and dairy foods (11.3\%). The average HETI score ranged from 22.6 to 93.1 (out of 100, mean 58.8 (sD 10.9)). There was a stepwise decrease in expenditure on discretionary foods by increasing HETI quintile, whereas expenditure on fruit and vegetables increased with HETI quintile $(P<0 \cdot 001)$. The HETI score was lower in obese compared with normal-weight participants $(55 \cdot 9 v$. 60.3; $P<0.01)$. Obese participants spent more on discretionary foods $(38.3 v .32 .7 \% ; P<0.01)$ and less on fruits and vegetables $(19.3 v .22 .2 \%$; $P<0.01)$. The HETI may be a useful tool to describe supermarket purchasing patterns and quality of the household food supply with application for consumer feedback to assist improved quality of foods purchased.
\end{abstract}

\section{Key words: Diet quality: Supermarkets: Food supply}

Poor eating habits are one of the key drivers of overconsumption of energy, weight gain and obesity. Australians consume inadequate amounts of fruit, vegetables and whole grains and, on average, get about $35 \%$ of their energy from energy-dense, nutrient-poor discretionary food and beverage items $^{(1,2)}$. As a result, improving the food supply to support healthy food choices has been identified as a priority for Australian health promotion efforts and internationally ${ }^{(3,4)}$.

About $60 \%$ of Australian food retail expenditure is in the supermarket, indicating its potential as a key setting to influence the food supply ${ }^{(5)}$. Previously, supermarket purchases have been found to relate to dietary intakes, particularly at the household level ${ }^{(6,7)}$. For example, when compared with $4 \mathrm{~d}$ of weighed food record data, 1 month of shopping purchase information produced reasonable estimates about energy and fat intake ${ }^{(7)}$. Many nutrition interventions promoting the purchase of healthier foods have been trialled in the supermarket setting. Although the evidence is equivocal for the effectiveness of supermarket interventions focused on point-of-purchase dietary education and information provision ${ }^{(8,9)}$, the potential for success using an innovative approach in this setting has recently been revisited ${ }^{(10)}$.

Moreover, the large amount of supermarket purchase data collected as part of customer loyalty schemes over the past few decades is an emerging area of interest ${ }^{(11)}$. These data have potential to provide detailed, objective and prospective information about the household food supply ${ }^{(11)}$. Food purchase data have been used to estimate individual nutrient intakes ${ }^{(6)}$, to describe food category purchases of different households ${ }^{(12)}$ and to measure the impact of nutrition interventions ${ }^{(13,14)}$.

Shopping docket data could also be used to initiate and support efforts to improve the household food supply, providing shoppers with information about the healthiness of their purchases over time. However, a key issue is translating these 'big data' into a meaningful metric, which can potentially influence purchase behaviour. Although most supermarket initiatives assist shoppers by providing a means to compare products within a food category ${ }^{(15)}$, looking at the whole pattern of dietary purchases may prove to be more valuable ${ }^{(16)}$.

Abbreviations: AGHE, Australian Guide to Healthy Eating; HETI, Healthy Trolley Index.

* Corresponding author: Dr G. A. Hendrie, fax +618 8303 8899, email gilly.hendrie@csiro.au 
In light of the increased focus towards assessing the whole diet, a large number of diet quality indices have been designed to examine how closely dietary patterns align with evidencebased national dietary guidelines. These have mostly been applied to intake data obtained via traditional assessment methods ${ }^{(17,18)}$. Traditional dietary assessment methods have limitations; namely, they are resource intensive and subject to biases such as misreporting ${ }^{(19)}$. The use of food purchase information may overcome some of these issues. In addition, it is possible that through loyalty schemes shoppers could opt into nutrition education campaigns and be rewarded for healthier purchasing habits. However, a system of rating the healthfulness of a trolley of supermarket purchases, using existing supermarket big data systems, is necessary.

The aim of this study was to develop an index to estimate population diet quality using food purchase data. The Healthy Trolley Index (HETI) will estimate compliance with the Australian Guide to Healthy Eating (AGHE) that includes five core food groups of grains and cereals, dairy foods, meat and alternatives, fruit and vegetables and recommends limited amounts of all other discretionary food and beverages. However, it will use supermarket purchase data to estimate the quality of the food supply at the household level. As part of this development, associations between shopping trolley quality and the demographic characteristics and weight status of the shopper responsible for the month of food purchases will be explored.

\section{Methods}

Food purchase data detailing all purchases from a major supermarket chain in Australia were obtained over a period of 1 month (starting late April 2014) for a sample of 964 people through a customer loyalty rewards programme. Shoppers used a loyalty rewards card, allowing identification of the shopper, and some limited demographic variables. These data were collected as part of the baseline data for a healthy lifestyle worksite intervention conducted with staff from the corporate office of a large retail chain. Ethics approval for the study was given by CSIRO Animal Food and Health Sciences Human Research Low Risk Review Panel (approval number LR14/01).

Demographic and anthropometric data including age, sex and self-reported height and weight were collected for the majority of participants. BMI was calculated, and individuals with extreme values were excluded ( $n$ 41). This included those who were underweight $\left(\mathrm{BMI}<18.5 \mathrm{~kg} / \mathrm{m}^{2}\right.$ ) or who reported a BMI $>100 \mathrm{~kg} / \mathrm{m}^{2}$. BMI was categorised into three weight status groups consistent with the World Health Organization ${ }^{(20)}$ cut-offs. Age was categorised into three groups consistent with those used in the latest Australian Health Survey (19-30, 31-50 and $51-70$ years)

\section{Measures}

Food purchase data. The following information describing purchases was available in an electronic format: customer ID, transaction date, category description, item description, basket quantity (the number of items) and transaction amount.

Category description referred to major groupings into which the supermarket chain assigned products, largely based on the product's location within the store (see Table 1 for examples). There were a total of 184 category descriptions, of which 108 referred to food and beverage products included in this analysis (seventy six non-food categories were excluded). The supermarket categorisation largely follows the displays of food in store. For example, all chilled yoghurts and desserts are in the same supermarket category. The item description provided more detailed information about the product, such as brand, package size and flavour variant. Transaction amount listed the cost of the product, and basket quantity listed the number of products purchased or the weight of fresh produce items.

Development of the Healthy Trolley Index scores. The AGHE provides dietary recommendations of intakes (number of servings and serve sizes) for core foods to ensure most Australians meet their nutrient requirements for health and well-being. The guidelines also include an allowance for noncore, discretionary foods, which are non-essential, as they are high in fat, salt and sugar but included to increase variety and enjoyment ${ }^{(21)}$. The HETI was developed to estimate compliance of monthly food purchases to these dietary recommendations. Each category description group, using the supermarket coding categories, was assigned to one of the five core food groups described in the AGHE (fruit, vegetables, grains, meat and dairy foods; see Table 1). The category descriptions considered to include discretionary foods were assigned to seven subgroups within the HETI discretionary food group (Table 1). Some category descriptions contained a mix of both core and non-core foods, and were assigned based on the most predominant items (e.g. chilled desserts contained $80 \%$ core dairy foods and $20 \%$ cream/mousse desserts, and thus they were assigned to dairy foods). Assigning category descriptions to core and non-core food groups was initially performed by two researchers, with another two researchers resolving any discrepancies.

There were some category description groups that did not clearly fit any AGHE food group or have a recommended intake, such as core food mixed dishes, and tea and coffee. An allowance for unsaturated fats is included as part of the core foods in the AGHE, but saturated fats are part of the discretionary food group. The category description of fats and oils included a mix of 'healthy' and 'unhealthy' fats. As these category descriptions did not have a clear position within the dietary recommendations and contributed a small proportion to total food expenditure, they were excluded in the development of the HETI scoring system. However, mixed dishes that were considered non-core contributed a greater proportion to expenditure and were included in the analysis.

Monthly expenditure per HETI food group was summed and presented as a percentage of total monthly food expenditure per shopper (i.e. expenditure per food group/monthly food expenditure $\times 100$ ). A proportion of expenditure was estimated for each of the five core food groups, and discretionary foods. This approach of using proportions to estimate the 
Table 1. Description of the Healthy Trolley Index (HETI) components and scoring criteria

\begin{tabular}{|c|c|c|c|c|}
\hline AGHE food group & HETI food group & Examples of category descriptions included & Examples of included foods & Target \\
\hline Grains and cereals & Grains and cereals & $\begin{array}{l}\text { Pasta, rice, in-store bread, bread rolls and fresh } \\
\text { bread, cereal, bakery bought in }\end{array}$ & $\begin{array}{l}\text { Pasta, rice, flour, bread, breakfast cereals, } \\
\text { crumpets, English muffins, raisin bread }\end{array}$ & $\begin{array}{l}\text { AGHE target }{ }^{\star}=6 \text { serves } \\
\text { HETI benchmark } \dagger=28 \%\end{array}$ \\
\hline Meat and alternatives & Meat and alternatives & $\begin{array}{l}\text { Seafood-meat, beef, pork, poultry - frozen, eggs, } \\
\text { nuts seeds/dried }\end{array}$ & $\begin{array}{l}\text { Fresh, smoked and canned seafood, fresh } \\
\text { and/or marinated beef, lamb, pork, } \\
\text { poultry, game meats, barbecued chicken, } \\
\text { eggs, tofu, tempeh, vegetarian meat } \\
\text { substitutes, nuts, seeds }\end{array}$ & $\begin{array}{l}\text { AGHE target }=2.75 \text { serves } \\
\text { HETI benchmark }=13 \%\end{array}$ \\
\hline Dairy foods and alternatives & Dairy foods & $\begin{array}{l}\text { Grocery milk, Gourmet cheese, cheese dairy, } \\
\text { chilled desserts }\end{array}$ & $\begin{array}{l}\text { Refrigerated and long-life milk, cheese, } \\
\text { yoghurt, cream, mousse, custard }\end{array}$ & $\begin{array}{l}\text { AGHE target }=2.5 \text { serves } \\
\text { HETI benchmark }=12 \%\end{array}$ \\
\hline Fruit & Fruit & Fruit snacks, fruit - shelf stable, dried fruit/nuts & $\begin{array}{l}\text { Fresh, canned and dried fruit, packaged fruit } \\
\text { nut and seed mixes }\end{array}$ & $\begin{array}{l}\text { AGHE target }=2 \text { serves } \\
\text { HETI benchmark }=9 \%\end{array}$ \\
\hline Vegetables & Vegetables & $\begin{array}{l}\text { Canned vegetables, frozen vegetables hard } \\
\text { vegetables and mushrooms, soft vegetables }\end{array}$ & $\begin{array}{l}\text { Frozen vegetables, frozen potato chips and } \\
\text { wedges, fresh vegetables, canned } \\
\text { vegetables, salad vegetables }\end{array}$ & $\begin{array}{l}\text { AGHE target }=5.5 \text { serves } \\
\text { HETI benchmark }=26 \%\end{array}$ \\
\hline \multirow[t]{8}{*}{ Discretionary } & $\begin{array}{l}\text { Discretionary: mixed dish, mainly } \\
\text { non-core }\end{array}$ & $\begin{array}{l}\text { Hot pies and foods, convenience frozen, meals, } \\
\text { heat and eat frozen }\end{array}$ & $\begin{array}{l}\text { Frozen and refrigerated pies, sausage rolls, } \\
\text { pizzas, chicken nuggets, battered fish, } \\
\text { television dinners, curries, pastas, Asian, } \\
\text { Indian and Mexican meal bases }\end{array}$ & $\begin{array}{l}\text { AGHE target }=2.75 \text { serves } \\
\text { HETI benchmark }=12 \%\end{array}$ \\
\hline & Discretionary: savoury snacks & $\begin{array}{l}\text { Antipasto/olive dip/pate, snacks, instant noodles, } \\
\text { entertainment }\end{array}$ & $\begin{array}{l}\text { Olives, sundried tomatoes, pate, potato } \\
\text { chips, maize chips, instant noodles, dips }\end{array}$ & \\
\hline & Discretionary: confectionery & $\begin{array}{l}\text { Boxed chocolates, confectionery, bars gum pocket } \\
\text { pack, ice cream }\end{array}$ & $\begin{array}{l}\text { Chocolate, lollies, chewing gum, jelly, } \\
\text { flavoured powders and syrups for milk } \\
\text { drinks, nut bars, ice cream, sugar, } \\
\text { artificial sweeteners }\end{array}$ & \\
\hline & $\begin{array}{l}\text { Discretionary: sugar-sweetened } \\
\text { beverages }\end{array}$ & Soft drinks, cordial, energy/sport/iced tea, juices & $\begin{array}{l}\text { Soft drinks, cordial, energy drinks, iced tea, } \\
\text { juices and fruit drinks, non-alcoholic } \\
\text { champagne }\end{array}$ & \\
\hline & Discretionary: alcohol & Wine, spirits, beer & Wine, spirits, beer & \\
\hline & Discretionary: processed meat & Ham/bacon, sausages, sliced meats, small goods & $\begin{array}{l}\text { Ham, bacon, sausages, devon, salami, fritz, } \\
\text { frankfurts, cocktail sausages, chorizo, } \\
\text { other cured meats }\end{array}$ & \\
\hline & $\begin{array}{l}\text { Discretionary: non-core baked } \\
\text { goods }\end{array}$ & $\begin{array}{l}\text { Baking mixes, bakery packaged cake, biscuits and } \\
\text { cookies, in-store cake, patisserie }\end{array}$ & $\begin{array}{l}\text { Baking mix bases, cakes, biscuits, pastries, } \\
\text { hot cross buns, slices }\end{array}$ & \\
\hline & $\begin{array}{l}\text { Discretionary: commercial } \\
\text { spreads and sauces }\end{array}$ & $\begin{array}{l}\text { Meal bases, salad dressings, sauces/relish, } \\
\text { spreads }\end{array}$ & $\begin{array}{l}\text { Meal bases, salad dressings, mayonnaise, } \\
\text { relish, sauces including soy/tomato/ } \\
\text { barbecue/sweet chilli and so on }\end{array}$ & \\
\hline \multirow[t]{3}{*}{$\begin{array}{l}\text { Other foods not included in } \\
\text { HETI scoring }\end{array}$} & Other & Tea, coffee, vinegar, spices/herbs & $\begin{array}{l}\text { Herbal and black tea, coffee and flavouring } \\
\text { powder mixes, pickled vegetables, } \\
\text { vinegar, herbs and spices, stock cubes }\end{array}$ & $\mathrm{N} / \mathrm{A}$ \\
\hline & Oils/spreads & Oils, chilled spreads & Oils, butter, margarine, Copha ${ }^{\mathrm{TM}}$ & $\mathrm{N} / \mathrm{A}$ \\
\hline & Mixed dish, mainly core & Soups, salads, sushi, canned meals & $\begin{array}{l}\text { Canned and powdered soups, pre-made } \\
\text { sandwiches, in-store café hot meals } \\
\text { (meat and three veg style), pre-made } \\
\text { salads, sushi, canned casseroles }\end{array}$ & $\mathrm{N} / \mathrm{A}$ \\
\hline
\end{tabular}

AGHE, Australian Guide to Healthy Eating.

* Serves is based on the recommendations in the AGHE, calculated as the average recomendation for men and women aged 19-50 years.

† HETI benchmark represents serves of food group as a proportion of total serves of food recommended (21.5 serves); that is: average recommendation/21.5 $\times 100$. 
healthfulness of the household food supply removes the need to account for household membership in the scoring system.

To compare expenditure patterns with recommended dietary patterns, the AGHE recommendations were presented as proportions. Given that the majority of participants in this study were aged 19-50 years, we used the average of the male and female food group recommendations for this age group as the benchmark. Within the AGHE, a range of recommended serves for discretionary foods is provided, which is dependent on the individual's current weight status, stature and physical activity level $^{(21)}$. To allow flexibility and the greatest opportunity to score well, we used the upper limit of this range as the benchmark, which was 2.75 serves (Table 1 ).

To generate a HETI score, the proportion of expenditure was compared with the benchmark for each food group, and a proportion score out of 10 calculated. The HETI benchmark represents serves of the food group as a proportion of total serves of food recommended ( 21.5 serves); that is: average recommendation $/ 21.5 \times 100$. If the proportion of monthly expenditure per food group was equal to or greater than the recommended proportion, a maximum score of 10 was assigned. For expenditure below the benchmark, a score was assigned proportionally. For discretionary foods, participants received a maximum score if expenditure was less than the recommended proportion, and diminished proportionally as their percentage of expenditure increased beyond the recommendation (Table 1).

Example calculation of the HETI score:

\begin{tabular}{lc}
\hline $\begin{array}{l}\text { Receipt data: monthly } \\
\text { expenditure: }\end{array}$ & HETI calculation: \\
$\begin{array}{l}\text { Beef }=\$ \text { AU29.00 } \\
\text { Poultry }- \text { frozen }=\$ \text { AU14.00 }\end{array}$ & $\begin{array}{c}\text { Expenditure on meat as a } \\
\text { proportion of total monthly } \\
\text { Eggs }=\$ \text { AU5.00 } \\
500 \times 100=9.6 \%\end{array}$ \\
$\begin{array}{l}\text { Total meat and } \\
\text { alternatives }=\$ \text { AU } 48.00\end{array}$ & HETI benchmark for meat $=13 \%$ \\
$\begin{array}{l}\text { Total food } \\
\text { expenditure }=\$ \text { AU500 }\end{array}$ & $\begin{array}{c}\text { HETI score for meat }=9.6 / 13 \times 10 \\
=7.4 \text { out of } 10\end{array}$ \\
\hline
\end{tabular}

The total HETI score gave equal weighting to each food group, by summing all six food group scores (total out of 60 ) and converting to a score out of 100 (by multiplying by 5/3). Higher HETI scores indicated greater compliance with dietary recommendations

Statistical analyses. Participants who spent $<$ AU100 on food over the 1-month period were excluded ( $n$ 87), as this was below the average food expenditure of the lowest income quintile in Australia ${ }^{(22)}$, and therefore deemed unlikely to represent usual household food supply.

Transaction date was used to calculate the number of shopping days per participant over 1 month, and tertiles were created to examine low-, medium- and high-frequency shoppers.

Mean expenditure and HETI scores per food group and overall for the month were calculated. Quintiles of HETI score were created (Q1 - lowest compliance to Q5 - highest compliance), and associations between HETI quintile, age, sex (available for 512/836 participants), body weight status, frequency of shopping (Q1 - lowest frequency to Q3 - highest frequency) and proportion of expenditure were explored. We also examined how expenditure on various food groups differed by HETI score, and by demographic characteristics and weight status.

Estimates are presented as means and standard deviations. Differences between HETI quintiles were examined using one-way ANOVA with Bonferroni's post hoc tests (significance level $P$ value $<0 \cdot 01$ ). Differences in shopping frequency by weight status were compared using $\chi^{2}$ test. All data coding and analysis was undertaken using SPSS statistical software package version 22.0 (IBM Corporation) $^{(23)}$.

\section{Results}

Shopping data of 1 month were available for 836 adults aged 19-65 years, most of them aged between 31 and 50 years (mean $37 \cdot 6$ (sD 9.3)). Of the participants who reported sex, $56 \%$ were female. The mean BMI of the sample was 27.9 (SD 6.6) kg/m², with the majority of participants being overweight $(35 \%)$ or obese (28\%), and living with a partner (40\%) or family (45\%). Three BMI values calculated from reported height and weight were $>50 \mathrm{~kg} / \mathrm{m}^{2}$, and while outside the expected range these individuals did not skew the data and were included. On average, participants spent \$AU669 at the supermarket over the month, $77 \%$ of which was on food (mean \$AU517 (SD 354)).

Participants spent the greatest proportion of their monthly food expenditure on discretionary foods $(34.8 \%)$, followed by meat and alternatives (17.0\%), vegetables (13.5\%) and dairy foods $(11.3 \%)$ (Table 2 ). Within the discretionary foods category, participants spent the greatest proportion on confectionary $(8.5 \%)$ and non-core mixed dishes (6.3\%), and about $4-5 \%$ each on sugar-sweetened beverages, processed meat and baked goods.

The average HETI score was 58.8 (sD 10.9) (range: 22.6-93.1/ out of 100). The percentage of participants meeting the benchmark (i.e. scoring 10 out of 10) for a food group was highest for meat and alternatives $(62.7 \%)$ and lowest for grains $(0.2 \%$ of the sample). In addition, very few people met the benchmark for vegetables (5.0\%) and discretionary foods (1.8\%).

Examination of expenditure by HETI quintiles shows a stepwise decrease in expenditure on discretionary foods by increasing HETI score quintile: that is, as overall shopping trolley quality increased, expenditure on discretionary foods decreased $(P<0 \cdot 001)$. The opposite was true for fruit and vegetables: as overall trolley quality increased, so did expenditure on fruit and vegetables. Although significant differences were seen across quintiles for all other food groups, the pattern of expenditure across all quintiles was not always consistent. For example, participants in the lowest quintile spent a q1significantly lower proportion of their monthly expenditure on grains and dairy foods than those in the highest quintile, and significantly less on meat than all other groups $(P<0 \cdot 001$; Table 2). 
Table 2. Total monthly expenditure and mean proportion of food expenditure per food group by Healthy Trolley Index (HETI) score quintile (Q) (Mean values and standard deviations; $n$ 836)

\begin{tabular}{|c|c|c|c|c|c|c|c|c|c|c|c|c|c|c|}
\hline & \multicolumn{13}{|c|}{ HETI score quintile } & \multirow[b]{3}{*}{$P+$} \\
\hline & & \multicolumn{2}{|c|}{ Overall } & \multicolumn{2}{|c|}{ Q1 $(n$ 167) } & \multicolumn{2}{|c|}{ Q2 ( $n$ 167) } & \multicolumn{2}{|c|}{ Q3 ( $n$ 168) } & \multicolumn{2}{|c|}{ Q4 ( $n$ 167) } & \multicolumn{2}{|c|}{ Q5 (n 167) } & \\
\hline & & Mean & SD & Mean & SD & Mean & SD & Mean & SD & Mean & SD & Mean & SD & \\
\hline Monthly food expenditure $(\$ A U)$ & & $517 \cdot 3$ & $354 \cdot 1$ & $418 \cdot 8$ & $319 \cdot 7$ & $551 \cdot 0$ & 343.5 & $525 \cdot 4$ & $299 \cdot 3$ & $592 \cdot 7$ & $450 \cdot 7$ & $498 \cdot 7$ & $316 \cdot 4$ & $0.001 \mp \S$ \\
\hline \multirow[t]{3}{*}{ HETI score $(/ 100)$} & & 58.8 & $10 \cdot 9$ & $42 \cdot 7$ & $6 \cdot 7$ & 53.5 & 1.9 & $59 \cdot 8$ & 1.6 & $65 \cdot 1$ & 1.6 & $72 \cdot 8$ & $4 \cdot 1$ & $<0.001^{*}$ \\
\hline & \multicolumn{13}{|c|}{ Proportion of monthly food expenditure } & \multirow[b]{3}{*}{$P+$} \\
\hline & \multicolumn{3}{|c|}{ Overall } & \multicolumn{2}{|c|}{ Q1 (n 167) } & \multicolumn{2}{|c|}{ Q2 (n 167) } & \multicolumn{2}{|c|}{ Q3 (n 168) } & \multicolumn{2}{|c|}{ Q4 (n 167) } & \multicolumn{2}{|c|}{ Q5 (n 167) } & \\
\hline benchmark) & $\%$ & Mean & SD & Mean & SD & Mean & SD & Mean & SD & Mean & SD & Mean & SD & \\
\hline Grains/cereals & 0.2 & $7 \cdot 9$ & $4 \cdot 2$ & $7 \cdot 1$ & $4 \cdot 3$ & $7 \cdot 4 \dagger$ & 3.8 & $8 \cdot 1$ & $4 \cdot 1$ & 7.9 & $4 \cdot 2$ & $8 \cdot 8$ & 4.5 & $0.003 \| \mathbb{1}$ \\
\hline Meat and alternatives & $62 \cdot 7$ & $17 \cdot 0$ & 9.5 & $13 \cdot 2$ & 11.2 & $18 \cdot 1$ & $10 \cdot 8$ & $17 \cdot 3$ & 8.9 & 18.4 & 7.6 & 18.2 & 7.6 & $<0.001 \mp \S \|^{\star *}$ \\
\hline Dairy foods & 38.4 & $11 \cdot 3$ & 5.8 & $9 \cdot 7$ & $7 \cdot 0$ & $10 \cdot 9$ & $6 \cdot 2$ & $10 \cdot 6$ & $5 \cdot 0$ & $11 \cdot 7$ & 4.7 & 13.7 & $5 \cdot 3$ & 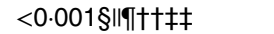 \\
\hline Fruit & $37 \cdot 6$ & $8 \cdot 1$ & $5 \cdot 7$ & $3 \cdot 0$ & $4 \cdot 3$ & $6 \cdot 2$ & 5.5 & 8.9 & $5 \cdot 0$ & $10 \cdot 6$ & $5 \cdot 8$ & $11 \cdot 2$ & $4 \cdot 3$ & 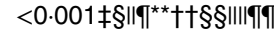 \\
\hline Vegetables & $5 \cdot 0$ & 13.5 & $7 \cdot 0$ & $8 \cdot 6$ & 5.8 & 11.5 & $5 \cdot 3$ & $13 \cdot 0$ & $5 \cdot 2$ & 14.8 & $6 \cdot 4$ & 19.5 & $7 \cdot 0$ & $<\left.0.001 \mp \S\|\|\right|^{\star \star} \dagger \dagger \ddagger \ddagger\|\| \mid$ \\
\hline Discretionary foods ${ }^{\star * \star}$ & 1.8 & 34.8 & $12 \cdot 3$ & $48 \cdot 6$ & $12 \cdot 6$ & 38.6 & $9 \cdot 0$ & 34.5 & $6 \cdot 9$ & 29.8 & $6 \cdot 6$ & $22 \cdot 3$ & $6 \cdot 4$ & $<0.001^{*}$ \\
\hline Non-core mixed dishes & & $6 \cdot 3$ & $5 \cdot 7$ & 9.2 & 8.3 & 7.3 & $5 \cdot 6$ & $6 \cdot 2$ & 4.4 & $5 \cdot 2$ & $4 \cdot 2$ & 3.5 & $3 \cdot 1$ & $<0.001$ \\
\hline Savoury snacks & & 3.5 & 3.0 & 4.9 & $4 \cdot 2$ & 3.4 & $2 \cdot 6$ & 3.4 & $2 \cdot 7$ & $3 \cdot 2$ & $2 \cdot 6$ & $2 \cdot 4$ & $2 \cdot 2$ & $<0.001$ \\
\hline \multirow[t]{4}{*}{ Confectionery } & & 8.5 & $6 \cdot 00$ & $11 \cdot 2$ & $8 \cdot 0$ & $9 \cdot 7$ & $5 \cdot 8$ & $8 \cdot 2$ & $5 \cdot 4$ & $7 \cdot 7$ & $4 \cdot 6$ & $5 \cdot 7$ & $4 \cdot 2$ & $<0.001$ \\
\hline & \multicolumn{13}{|c|}{ HETI score quintile } & \\
\hline & & \multicolumn{2}{|c|}{ Overall } & \multicolumn{2}{|c|}{ Q1 ( $n$ 167) } & \multicolumn{2}{|c|}{ Q2 (n 167) } & \multicolumn{2}{|c|}{ Q3 $(n$ 168) } & \multicolumn{2}{|c|}{ Q4 (n 167) } & \multicolumn{2}{|c|}{ Q5 ( $n$ 167) } & \\
\hline & & Mean & SD & Mean & SD & Mean & SD & Mean & SD & Mean & SD & Mean & SD & $P \dagger$ \\
\hline Sugar-sweetened beverages & & 4.9 & $5 \cdot 7$ & $9 \cdot 0$ & $9 \cdot 0$ & $5 \cdot 3$ & 5.0 & 4.8 & 4.0 & $3 \cdot 3$ & $2 \cdot 9$ & $2 \cdot 3$ & $2 \cdot 6$ & $<0.001$ \\
\hline Alcohol & & 0.1 & 1.2 & 0.2 & 1.9 & 0.2 & 1.8 & 0.0 & 0.0 & 0.1 & 0.8 & 0.0 & 0.0 & NS \\
\hline Processed meat & & 4.5 & $3 \cdot 8$ & $5 \cdot 3$ & 4.8 & $5 \cdot 0$ & $4 \cdot 2$ & 4.6 & $3 \cdot 3$ & $4 \cdot 2$ & 3.4 & 3.5 & $2 \cdot 9$ & $<0.001$ \\
\hline Non-core baked goods & & $4 \cdot 1$ & 3.5 & 5.5 & 4.5 & 4.4 & 3.6 & 4.5 & 3.7 & 3.6 & 2.5 & $2 \cdot 6$ & $2 \cdot 1$ & $<0.001$ \\
\hline Commercial spread/sauce & & $2 \cdot 8$ & $2 \cdot 3$ & $3 \cdot 2$ & $3 \cdot 0$ & 3.4 & $2 \cdot 6$ & $2 \cdot 8$ & $2 \cdot 0$ & 2.5 & 1.7 & $2 \cdot 2$ & $1 \cdot 7$ & $<0.001$ \\
\hline
\end{tabular}

* All quintiles are significantly different.

† Significance of the differences between quintiles were assessed using ANOVA with Bonferroni's post hoc adjustments. Significance of pair-wise comparisons is denoted with symbols.

¥ Indicates that the difference between Q1 and Q2 is significant.

$\S \mathrm{Q1} v$. Q4.

॥ Q1 v. Q5.

I Q2 v. Q5.

** Q1 v. Q3.

†† Q3 v. Q5.

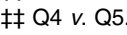

§ Q2 v. Q3.

IIII Q2 v. Q4.

शा Q3 v. Q4.

${ }_{\star \star \star}$ The pair-wise comparisons for subgroups of discretionary foods are not reported

More detailed sub-group analysis showed that higher HETI scores were associated with a greater proportion of expenditure on rice, seafood, non-meat protein sources (nuts, tofu, eggs), cheese, chilled desserts (mainly yoghurt), fresh fruit, dried fruit, frozen fruit, fresh vegetables, canned vegetables and salad leaves (data not shown). In contrast, lower scores were associated with canned, frozen and refrigerated convenience meals (mainly frozen pizzas, pies, garlic breads, chicken nuggets, television dinners, pre-prepared pasta dishes and canned casseroles), instant noodles, snacks (mainly potato and maize chips), chocolate bars, energy/sports drinks, soft drinks, juices, biscuits and cakes and meal bases. Interestingly, the lowest HETI quintile spent a significantly greater proportion on frozen vegetables, which largely comprised processed potato products (e.g. oven fries).
Table 3 shows the proportion of expenditure on food groups by various demographic variables. Overall HETI scores were significantly higher in male than in female participants $(60.0 \mathrm{v}$. 57.6; $P \leq 0.01)$ and significantly lower in obese compared with normal-weight and overweight participants (55.9 v. 60.3 and 59.9; $P \leq 0 \cdot 001)$. Male participants spent a greater proportion of their expenditure on grains and dairy foods and significantly less on discretionary foods. There was a stepwise increase in expenditure on discretionary foods with increasing weight status, with obese participants spending more on these foods than other weight status groups. Although obese participants spent significantly more on discretionary foods $(38.3 v$ v. 32.7; $P \leq 0.001)$, they spent significantly less on fruit (7.2 v. 8.8; $P \leq 0.01)$ and vegetables compared with normal-weight 
Table 3. Healthy Trolley Index (HETI) score and mean percentage of food expenditure per Healthy Eating Index food groups by sex, age group, weight status, frequency of shopping and living arrangements

(Numbers; mean values and standard deviations)

\begin{tabular}{|c|c|c|c|c|c|c|c|c|c|c|c|c|c|c|c|}
\hline & \multirow[b]{3}{*}{$n$} & \multicolumn{14}{|c|}{ Percentage of food expenditure $†$} \\
\hline & & \multicolumn{2}{|c|}{ HETI score $(/ 100)$} & \multicolumn{2}{|c|}{ Grains/cereals } & \multicolumn{2}{|c|}{ Meat and alternatives } & \multicolumn{2}{|c|}{ Dairy foods } & \multicolumn{2}{|c|}{ Fruit } & \multicolumn{2}{|c|}{ Vegetables } & \multicolumn{2}{|c|}{ Discretionary } \\
\hline & & Mean & SD & Mean & SD & Mean & SD & Mean & $\mathrm{SD}$ & Mean & SD & Mean & SD & Mean & SD \\
\hline \multicolumn{16}{|l|}{ Sex } \\
\hline Female & 287 & $57 \cdot 6$ & 11.5 & 7.5 & $4 \cdot 1$ & $17 \cdot 4$ & $9 \cdot 3$ & $10 \cdot 7$ & $5 \cdot 8$ & 7.6 & $5 \cdot 7$ & $13 \cdot 6$ & 6.9 & $35 \cdot 9$ & $12 \cdot 5$ \\
\hline Male & 225 & $60 \cdot 0^{*}$ & $10 \cdot 2$ & $8.6^{*}$ & 4.6 & $17 \cdot 7$ & $10 \cdot 2$ & $12 \cdot 4^{\star}$ & $6 \cdot 2$ & 8.2 & 5.4 & $12 \cdot 8$ & 6.5 & $32 \cdot 9^{*}$ & 11.7 \\
\hline \multicolumn{16}{|l|}{ Age group } \\
\hline $19-30$ years & 205 & $58 \cdot 8$ & 11.5 & $7 \cdot 4$ & $4 \cdot 2$ & $18 \cdot 3 \ddagger$ & $9 \cdot 8$ & $10 \cdot 7$ & $5 \cdot 8$ & $7 \cdot 3$ & $5 \cdot 3$ & $15 \cdot 0 \ddagger$ & $7 \cdot 2$ & 34.4 & $13 \cdot 7$ \\
\hline $31-50$ years & 544 & $58 \cdot 7$ & $10 \cdot 8$ & 7.9 & $4 \cdot 3$ & $16 \cdot 3$ & 9.4 & $10 \cdot 7$ & 5.9 & 8.4 & $5 \cdot 6$ & $12 \cdot 9$ & $7 \cdot 0$ & 35.4 & 11.9 \\
\hline $51-70$ years & 87 & 59.5 & $10 \cdot 3$ & $8 \cdot 6$ & 3.8 & $18 \cdot 5$ & $9 \cdot 3$ & $10 \cdot 6$ & 5.5 & 8.5 & $7 \cdot 1$ & $13 \cdot 0$ & $6 \cdot 1$ & 31.9 & $10 \cdot 8$ \\
\hline \multicolumn{16}{|l|}{ Weight status } \\
\hline Healthy weight & 309 & $60 \cdot 3 \S \|$ & $11 \cdot 8$ & 7.9 & 4.4 & 17.5 & $10 \cdot 2$ & $11 \cdot 0$ & $5 \cdot 9$ & $8 \cdot 8 \|$ & 6.4 & $14 \cdot 8 \|$ & $7 \cdot 6$ & $32 \cdot 7 \|$ & $13 \cdot 7$ \\
\hline Overweight & 294 & $59 \cdot 9$ & $9 \cdot 2$ & $8 \cdot 0$ & 4.0 & $17 \cdot 4$ & 9.0 & $11 \cdot 8$ & 5.9 & $8 \cdot 2$ & $5 \cdot 4$ & $13 \cdot 2$ & $6 \cdot 3$ & $34 \cdot 1$ & $10 \cdot 1$ \\
\hline Obese & 233 & 55.9 & $11 \cdot 1$ & $7 \cdot 7$ & $4 \cdot 3$ & $16 \cdot 0$ & $9 \cdot 1$ & $11 \cdot 1$ & $5 \cdot 7$ & $7 \cdot 2$ & $4 \cdot 8$ & $12 \cdot 1$ & $6 \cdot 6$ & $38 \cdot 3$ & $12 \cdot 2$ \\
\hline \multicolumn{16}{|l|}{ Frequency of shopping } \\
\hline Lowest frequency & 298 & $58 \cdot 6$ & $11 \cdot 2$ & $8 \cdot 0$ & 4.7 & $16 \cdot 9$ & $10 \cdot 3$ & 11.5 & $6 \cdot 7$ & $8 \cdot 2$ & $5 \cdot 7$ & $14 \cdot 0$ & 7.5 & 33.9 & $12 \cdot 6$ \\
\hline Medium frequency & 266 & $59 \cdot 7$ & $10 \cdot 0$ & 7.6 & 4.0 & $17 \cdot 9$ & $9 \cdot 8$ & 11.0 & $5 \cdot 3$ & $8 \cdot 7$ & $5 \cdot 9$ & $13 \cdot 7$ & 6.9 & 33.4 & 11.7 \\
\hline Highest frequency & 272 & $58 \cdot 1$ & 11.4 & 8.0 & $4 \cdot 0$ & $16 \cdot 3$ & $8 \cdot 3$ & 11.5 & $5 \cdot 3$ & $7 \cdot 6$ & $5 \cdot 5$ & $12 \cdot 6$ & $6 \cdot 4$ & $37 \cdot 1 \Phi^{\star *}$ & $12 \cdot 3$ \\
\hline \multicolumn{16}{|l|}{ Living arrangements } \\
\hline I live alone & 84 & $55.8 \dagger \dagger$ & $12 \cdot 4$ & 6.2†††† & $4 \cdot 0$ & 15.3††キ† & $11 \cdot 2$ & $11 \cdot 6$ & $7 \cdot 6$ & 8.4 & $6 \cdot 2$ & $14 \cdot 0$ & $8 \cdot 3$ & $36 \cdot 0$ & $13 \cdot 6$ \\
\hline With spouse/partner & 336 & 59.9 & $10 \cdot 6$ & $7 \cdot 7$ & 4.5 & $18 \cdot 5$ & 9.7 & $10 \cdot 7 \S \S$ & $5 \cdot 2$ & $7 \cdot 3$ & $5 \cdot 1$ & $15 \cdot 0$ & 7.5 & $32.7 \S \S$ & $12 \cdot 3$ \\
\hline With family & 376 & $58 \cdot 2$ & $10 \cdot 7$ & 8.5 & 3.9 & $15 \cdot 8$ & $8 \cdot 8$ & $12 \cdot 0$ & $6 \cdot 0$ & 8.5 & $6 \cdot 1$ & $11 \cdot 7 \ddagger \ddagger \S \S|| I \mid$ & $5 \cdot 7$ & $36 \cdot 6$ & 11.9 \\
\hline Other & 40 & $70 \cdot 0$ & 11.5 & $6 \cdot 9$ & $4 \cdot 3$ & 19.5 & $7 \cdot 7$ & $9 \cdot 4$ & 4.0 & 8.7 & $5 \cdot 9$ & $15 \cdot 9$ & 6.9 & $32 \cdot 3$ & $11 \cdot 0$ \\
\hline
\end{tabular}

* All groups are significantly different.

† Significance of the differences between quintiles were assessed using ANOVA with Bonferroni's post hoc adjustments. Significance of pair-wise comparisons is denoted with symbols $(P<0.01)$

‡ Difference between $19-30$ and $31-50$ is significant.

$\S$ Healthy weight $v$. overweight.

II Healthy weight $v$. obese.

I Low $v$. high frequency.

${ }^{\star \star}$ Medium $v$. high frequency.

†† Alone $v$. partner.

执 Alone $v$. family.

$\S \S$ Partner $v$. family.

IIII Family $v$. other.

participants $(12 \cdot 1 v \cdot 14 \cdot 8 ; P \leq 0 \cdot 001)$. In particular, obese participants spent a greater proportion on frozen convenience foods, chocolate bars, soft drinks, processed deli meats, biscuits and frozen vegetables (data not shown).

Young adults (19-30 years) spent a greater proportion of their monthly expenditure on meat and alternatives (18.3 $v$. $16.3 ; \quad P \leq 0.01)$ and vegetables $(15.0 \quad v .12 \cdot 9 ; \quad P \leq 0.001)$ compared with 31-50-year-olds. However, there were no significant differences in overall HETI scores between age groups.

An increased frequency of shopping occasions within the month was associated with a greater proportion spent on discretionary foods. Those participants in the highest tertile of shopping occasions spent significantly more on discretionary foods than those who shopped less often. Although mean BMI did not differ by shopping frequency, the proportions of obese $v$. normal weight in the high-frequency shoppers was significantly greater $\left(35 v .20 \% ; \chi^{2}=0.001\right)$. There were no differences in the frequency of shopping by age or sex. Those who lived alone had significantly lower HETI scores compared with those living with a spouse/partner $(55.8 v .59 \cdot 9 ; P<0.01)$. They spent less on grains/cereals and meat and alternatives compared with couples and families. Couples spent significantly less on discretionary items. Those living with family spent significantly less on vegetables compared with both those living alone or with a partner.

\section{Discussion}

The HETI has been developed as a tool to assess the healthiness of food purchases from a supermarket over 1 month. The index has been applied to electronic supermarket docket data in the format it is collected by the supermarket. It was deemed important to use the existing supermarket coding system, as it would be unfeasible to code each individual food, assign all the new foods as they come to market or to expect supermarket chains to redesign their system to fit with the AGHE categories. The HETI was developed to estimate compliance with the Australian nutrition recommendations. Thus, we found that higher HETI scores were related to greater expenditure on healthy foods including fruit, vegetables, dairy foods, meat and alternatives and grains and cereals, and lower expenditure on energy-dense, nutrient-poor discretionary foods. Interestingly, these findings are consistent with those of Hollywood et al. ${ }^{(24)}$ who found that shoppers perceived a healthy shop to include fruit, vegetables, seafood, dairy foods, eggs, juice and whole 
grain products, whereas an unhealthy shop was characterised by baked goods, high-fat snack foods, soft drinks, frozen and processed items and convenience products.

The comparison between expenditure and nutrition recommendations was based on proportions, and thus the proportion of total monthly expenditure per food group was compared with the recommended intake as a proportion of recommended total serves of food. Although there are limitations to this method, it does give an indication of where the balance of the food in the diet should be coming from. The suitability of using expenditure as the method for calculating food group proportions was reinforced when basket quantity counts of purchased items yielded similar HETI scores for shoppers. National data on food intakes are also consistent with the direction of our findings. For example, it is recommended that $26 \%$ of our total serves of food comes from vegetables; however, participants only spent $13 \%$ of their monthly expenditure on vegetables, and only $5 \%$ spent an adequate amount to meet the recommendation. Similarly, $40 \%$ of participants spent an adequate amount to meet the fruit recommendation. These results are supported by recent national intake data using 24-h recall, which suggest that $48 \%$ of Australian adults report meeting the fruit recommendation and $8 \%$ the vegetable recommendation ${ }^{(2)}$. Similar findings between methods have also been reported for discretionary foods. It has been estimated that $36 \%$ of Australian adults' energy intake comes from discretionary foods ${ }^{(1,2)}$, and we found that almost $35 \%$ of monthly food expenditure was spent on these energydense, nutrient-poor foods. It is encouraging that the current study using food expenditure data to capture the household food supply found similar percentages to those from Australian population surveys using traditional 24-h recall methods of dietary assessment. This offers some validity to using supermarket purchase data to estimate the HETI as a representation of household food supply.

Fruit, vegetables and discretionary foods held the strongest relationship with HETI score; that is, expenditure on fruit and vegetables increased in a stepwise manner with increasing quintile of shopping quality, whereas expenditure on discretionary foods decreased. This pattern of expenditure suggests that these households' food supply may not support healthy dietary choices. Indeed, we found that lower expenditure on fresh fruit and vegetables and higher expenditure on energy-dense, nutrientpoor discretionary foods characterised the supermarket purchases of obese individuals. Although all weight status groups spent more than one-third of their monthly expenditure on discretionary foods, obese individuals spent $38 \%$ - significantly more than other groups - and as a result had a lower-quality purchase pattern overall than normal-weight people in this sample. The prevalence of overweight and obesity in this sample population is consistent with the Australian population in 2011-2012 25 .

Previous research suggests that supermarket purchasing patterns are a proxy for food availability in the home ${ }^{(26,27)}$, and that food availability has been associated with weight status $^{(6,28)}$. Interestingly, however, relationships between higher energy intake, poor diet quality and weight status are not always supported in studies using traditional, self-reported methods of dietary assessment. Many have suggested that this is a consequence of misreporting and social biases, a phenomenon generally characterised by over-reporting of healthy foods and under-reporting of unhealthy foods, which is particularly common in some subgroups of the population such as women and obese adults ${ }^{(29,30)}$. Using food purchase data may overcome some of these issues ${ }^{(31)}$, as it is objective and prospective, and therefore does not rely on the usual issues associated with an individual's memory to recall foods consumed. Female participants often report better-quality dietary patterns than male participants ${ }^{(32,33)}$; however, we know that social desirability biases tend to vary by sex using traditional methodology for dietary data collection ${ }^{(2,30,34)}$. We found that male participants spent less on discretionary foods, and more on dairy foods and grains, resulting in a trend towards male shoppers obtaining higher HETI scores. As the HETI is free from reporting biases associated with these traditional methods, the findings in the present study indicate that perhaps the diets of female participants may not be as healthy as previously reported, although we acknowledge that the purchases may be for other household members such as children.

Participants who shopped more frequently tended to spend more over the month, and spend a greater proportion of this on discretionary foods. These participants were also more likely to be obese. The shopping environment, layout and positioning of foods within the supermarket means that each time consumers visit the store they battle marketing strategies to increase impulse purchasing and encourage the purchase of unhealthy foods ${ }^{(35)}$. In fact, discretionary foods and beverages are most likely to be purchased as a result of these tactics ${ }^{(35-37)}$. Restructuring the food environment, which shapes obesity, is one important part of the multidimensional approach needed to address obesity; however, commitment is required from all sectors including retailers, if the full potential of this is to be met ${ }^{(38)}$.

There are a number of strengths and limitations of this study, which need consideration. First, we applied the shopping quality scoring system to 1 month's worth of purchase data received directly from the supermarket. Data of 1 month were considered reasonable to represent 'usual' food purchases and capture some items bought infrequently. However, using data for a longer time period may better reflect habitual purchase habits. In light of translation and up-scaling this approach, we used the predefined category descriptions provided in the data set for coding foods into food groups consistent with the AGHE. However, there were some category descriptions groupings that included both healthy and less healthy versions of foods that would usually be included in the discretionary food group. In these cases, we allocated the whole category description food group based on the majority of food items within that group; for example the HETI is unable to distinguish between breakfast cereals, placing all varieties into an AGHE core food group, positively affecting the HETI score. In addition, this approach did not allow all aspects of the AGHE to be included in the HETI scoring system. For example, in Australia, there are recommendations to eat a variety of foods and that dairy foods are preferably low fat, and grains are mostly whole grain; however, our current approach did not distinguish foods at this level of detail. Further refinement is possible using the food item description; however, collaboration with supermarkets would be required to build this coding into their computer 
systems before being up-scaled and applied to a large data set. In addition, our scoring system did not penalise for excessive consumption. It has been recommended when designing a diet quality index for application at individual level, to apply scoring penalties for overconsumption of core foods that could have detrimental health impacts when eaten in excess ${ }^{(39-41)}$. The HETI expressed purchase patterns as a proportion based on expenditure, which may have influenced results differently for distinct foods groups. For example, foods within the grains group, such as rice or pasta, may be consumed daily but purchased in larger quantities. Thus, expenditure per month may not reflect consumption as well as it does for other foods. We found that compliance with this food group was very low, but this finding is supported by dietary intake data ${ }^{(42)}$. Nonetheless, future refinement of the index may improve the sensitivity of the scoring system across all food groups.

The emergence in popularity of smaller speciality stores such as greengrocers, bakeries, fishmongers and butchers means that for some shoppers an unknown proportion of fresh, healthy foods would not have been captured in their supermarket expenditure. On the other hand, although people are purchasing some takeaway type foods such as frozen pizzas, pies and frozen chicken and chips from supermarkets, meals purchased from takeaway outlets and restaurants are also not accounted for within this approach. Australians spend $>25 \%$ of weekly food expenditure on these foods ${ }^{(5)}$, and thus the index may exclude a significant proportion of likely unhealthy foods. Furthermore, this approach does not account for different proportions consumed by different household members, visitors to the home who consume some of this food and food wastage. In addition, although using proportional data reduces the need for information regarding the number and makeup of individuals in the household, the applicability of relationships between shopper demographics and HETI score may be limited. Despite these limitations, food sold in supermarkets makes a substantial contribution to the household diet. In Australia, we have two major supermarkets with a market share of $73 \%$ of the grocery sector ${ }^{(43)}$; therefore, the products they stock have a major influence on food purchases. Therefore, while shopping dockets may have limitations as a direct measure of intake, there is potential to use purchasing information as a proxy of intake at the group/household level.

Future research needs to validate the HETI scoring system against an alternative method of dietary assessment, and even with disease risk factors and biomarkers if possible to examine the diet-disease relationships. A self-administered online version of the 24-h recall will become available in Australia in future, and family members of the primary shopper could be invited to complete a number of recalls over a month to further validate the HETI scoring system. In addition, testing the sensitivity of the index to capture changes in food purchases over time would be warranted ${ }^{(44)}$. With the proposed refinements and established validity, there is potential to use such an index in consumer education programmes or supermarket offerings to improve the healthiness of food purchases to better align with public health recommendations. Payne et al. ${ }^{(10)}$ have demonstrated that properly targeted supermarket-based nutrition interventions may benefit both shoppers and retailers by guiding consumer purchases towards fruit and vegetable items without detrimentally affecting the income of the retailers.

Nonetheless, strong evidence for supermarket interventions, particularly those that provide nutrition education only at point of purchase, is somewhat lacking ${ }^{(8)}$, although interventions with a price intervention show more promise ${ }^{(13,45,46)}$. Nutrition education alone may not be adequate to drive real and sustained change to the household food supply. Emerging technologies might provide a vehicle to increase shopper engagement and collaboration between retailers and nutrition educators. This could affect eating habits at a population level. The HETI might be used to track changes in shoppers' purchases over time and goals set to improve the score with an education programme to assist.

\section{Conclusion}

The HETI was designed to assess the healthiness of food purchases by comparing expenditure with population dietary recommendations. We have shown that higher shopping quality over 1 month was associated with greater expenditure on healthy foods such as fruit and vegetables, and lower expenditure on energy-dense, nutrient-poor foods. Poor shopping quality was also associated with obesity. With further refinement and validation, and with the use of innovative technology that allows communication and education, the HETI may prove to be a useful tool to help shoppers move towards healthier food purchasing patterns at the supermarket.

\section{Acknowledgements}

This research received no specific grant from any funding agency, commercial or not-for profit sectors.

All authors contributed to the design of the study. A. T., F. W. and G. A. H. conducted the analysis and were responsible for preparing the manuscript. All authors have reviewed the manuscript and approve it for submission.

None of the authors has any conflicts of interest to declare.

\section{References}

1. Rangan AM, Schindeler S, Hector DJ, et al. (2009) Consumption of 'extra' foods by Australian adults: types, quantities and contribution to energy and nutrient intakes. Eur J Clin Nutr 63, $865-871$.

2. Australian Bureau of Statistics (2014) Australian Health Survey: Nutrition First Results - Foods and Nutrients, 2011-12. Canberra: ABS.

3. Swinburn B, Sacks G, Hall K, et al. (2011) The global obesity pandemic: shaped by global drivers and local environments. Lancet 378, 804-814.

4. National Preventative Health Taskforce (2009) Australia: the Healthiest Country by 2020 - National Preventative Health Strategy - The Roadmap for Action. Canberra: Commonwealth of Australia.

5. Department of Agriculture Fisheries and Forestry (2013) Australian Food Statistics. Canberra: Commonwealth of Australia.

6. Ransley J, Donnelly J, Botham H, et al. (2003) Use of supermarket receipts to estimate energy and fat content of food 
purchased by lean and overweight families. Appetite $\mathbf{4 1}$, 141-148.

7. Ransley JK, Donnelly JK, Khara TN, et al. (2001) The use of supermarket till receipts to determine the fat and energy intake in a UK population. Public Health Nutr 4, 1279-1286.

8. Escaron AL, Meinen AM, Nitzke SA, et al. (2013) Supermarket and grocery store-based interventions to promote healthful food choices and eating practices: a systematic review. Prev Chronic Dis 10, E50.

9. van 't Riet J (2013) Sales effects of product health information at points of purchase: a systematic review. Public Health Nutr 16, 418-429.

10. Payne CR, Niculescu M, Just DR, et al. (2014) Shopper marketing nutrition interventions. Physiol Behav 136, 111-120.

11. Tin ST, Mhurchu CN \& Bullen C (2007) Supermarket sales data: feasibility and applicability in population food and nutrition monitoring. Nutr Rev 65, 20-30.

12. Cullen K, Baranowski T, Watson K, et al. (2007) Food category purchases vary by household education and race/ethnicity: results from grocery receipts. J Am Diet Assoc 107, 1747-1752.

13. Ni Mhurchu C, Blakely T, Jiang Y, et al. (2009) Effects of price discounts and tailored nutrition education on supermarket purchases: a randomized controlled trial. Am J Clin Nutr $\mathbf{9 1}$, 736-747.

14. Ball K, McNaughton SA, Le H, et al. (2013) ShopSmart 4 Health - protocol of a skills-based randomised controlled trial promoting fruit and vegetable consumption among socioeconomically disadvantaged women. BMC Public Health 13, 466.

15. Sutherland LA, Kaley LA \& Fischer L (2010) Guiding stars: the effect of a nutrition navigation program on consumer purchases at the supermarket. Am J Clin Nutr 91, 1090s-1094s.

16. Hu FB. (2002) Dietary pattern analysis: a new direction in nutritional epidemiology. Curr Opin Lipidol 13, 3-9.

17. Golley RK, Hendrie GA \& McNaughton SA (2011) Scores on the dietary guideline index for children and adolescents are associated with nutrient intake and socio-economic position but not adiposity. I Nutr 141, 1340-1347.

18. Aljadani HM, Patterson A, Sibbritt D, et al. (2013) Diet quality, measured by fruit and vegetable intake, predicts weight change in young women. $J$ Obes 2013, 525161

19. Westerterp KR \& Goris AHC (2002) Validity of the assessment of dietary intake: problems of misreporting. Curr Opin Clin Nutr Metab Care 5, 489-493.

20. World Health Organization (2000) Obesity: Preventing and Managing the Global Epidemic, no. 894. Geneva: WHO.

21. National Health and Medical Research Council (2013) Australian Dietary Guidelines. Canberra: Commonwealth of Australia.

22. Australian Bureau of Statistics (2011) Household Expenditure Survey; Summary of Results 2009-2011. Canberra: Comonwealth of Australia.

23. IBM Corporation (2013) IMB SPSS Statistics for Windows. 22.0 ed. Armonk, NY: IBM Corporation.

24. Hollywood LE, Cuskelly GJ, O'Brien M, et al. (2013) Healthful grocery shopping. Perceptions and barriers. Appetite 70, 119-126.

25. Australian Bureau of Statistics (2011) Australian Health Survey: First Results 2011-12. Canberra: ABS

26. Moore LV, Roux AVD, Nettleton JA, et al. (2008) Associations of the local food environment with diet quality a comparison of assessments based on surveys and geographic information systems the multi-ethnic study of atherosclerosis. $\mathrm{Am} \mathrm{J}$ Epidemiol 167, 917-924.
27. French SA, Shimotsu ST, Wall M, et al. (2008) Capturing the spectrum of household food and beverage purchasing behavior: a review. J Am Diet Assoc 108, 2051-2058.

28. Morland K, Diez Roux AV \& Wing S (2006) Supermarkets, other food stores, and obesity: the atherosclerosis risk in communities study. Am J Prev Med 30, 333-339.

29. Rangan A, Allman-Farinelli M, Donohoe E, et al. (2014) Misreporting of energy intake in the 2007 Australian Children's Survey: differences in the reporting of food types between plausible, under- and over-reporters of energy intake. $J$ Hum Nutr Diet 27, 450-458.

30. Australian Bureau of Statistics (2014) Australian Health Survey: Users' Guide, 2011-13. Under-Reporting in Nutrition Surveys. Canberra: ABS.

31. Gibson R. (2005) Principles of Nutritional Assessment, 2nd ed. New York: Oxford University Press.

32. McNaughton SA, Ball K, Crawford D, et al. (2008) An index of diet and eating patterns is a valid measure of diet quality in an Australian population. J Nutr 138, 86-93.

33. Zarrin R, Ibiebele TI \& Marks GC (2013) Development and validity assessment of a diet quality index for Australians. Asia Pac J Clin Nutr 22, 177-187.

34. Hebert JR, Ma Y, Clemow L, et al. (1997) Gender differences in social desirability and social approval bias in dietary self-report. Am J Epidemiol 146, 1046-1055.

35. Nederkoorn C, Guerrieri R, Havermans R, et al. (2009) The interactive effect of hunger and impulsivity on food intake and purchase in a virtual supermarket. Int J Obes 33, 905-912.

36. Kline R, Graff S, Zellers L, et al. (2006) Beyond advertising controls: influencing junk-food marketing and consumption with policy innovations developed in tobacco control. Loyola Los Angel Law Rev 39, 603.

37. Harris JL, Pomeranz JL, Lobstein T, et al. (2009) A crisis in the marketplace: how foodmarketing contributes to childhood obesity and what can be done. Annu Rev Public Health 30, 211-225.

38. McKinsey Global Institute (2014) Overcoming obesity: an initial economic analysis. Discussion Paper, McKinsey Global Institute. http://www.mckinsey.com/insights/economic_studies/ how_the_world_could_better_fight_obesity (accessed October 2015).

39. English DR, MacInnis RJ, Hodge AM, et al. (2004) Red meat, chicken, and fish consumption and risk of colorectal cancer. Cancer Epidemiol Biomarkers Prev 13, 1509-1514.

40. Larsson SC, Rafter J, Holmberg L, et al. (2005) Red meat consumption and risk of cancers of the proximal colon, distal colon and rectum: the Swedish Mammography Cohort. Int J Cancer 113, 829-834.

41. Sesink AL, Termont DS, Kleibeuker JH, et al. (1999) Red meat and colon cancer: the cytotoxic and hyperproliferative effects of dietary heme. Cancer Res 59, 5704-5709.

42. Australian Bureau of Statistics (2014) Australian Health Survey: Nutrition First Results - Foods and Nutrients, 2011-12 Cereals and Cereal Products. Canberra: ABS.

43. Roy Morgan Research (2014) Market share narrows between coles and woolworths, while ALDI makes important gains, Article no. 5427, Roy Morgan Research, Melbourne, VIC.

44. Wirt A \& Collins CE (2009) Diet quality-what is it and does it matter? Public Health Nutr 12, 2473-2492.

45. Waterlander WE, de Boer MR, Schuit AJ, et al. (2013) Price discounts significantly enhance fruit and vegetable purchases when combined with nutrition education: a randomized controlled supermarket trial. Am J Clin Nutr 97, 886-895.

46. Liberato SC, Bailie R \& Brimblecombe J (2014) Nutrition interventions at point-of-sale to encourage healthier food purchasing: a systematic review. BMC Public Health 14, 919. 